\title{
PENGENDALIAN BANJIR KOTA PADANG MENGGUNAKAN METODE ZERO RUN OFF SYSTEM (STUDI KASUS DAS KURANJI)
}

\author{
Hendri Gustian ${ }^{1}$, Feri Arlius ${ }^{2}$, Rusnam ${ }^{2}$, dan Eri Gas Ekaputra ${ }^{2}$ \\ ${ }^{1}$ Mahasiswa Program Magister Teknik Pertanian, Universitas Andalas \\ ${ }^{2}$ Dosen Fakultas Teknologi Pertanian, Universitas Andalas \\ Email: hendrigustian63@gmail.com
}

\begin{abstract}
ABSTRAK
Banjir pada umumnya terjadi akibat faktor alam seperti intensitas hujan yang tinggi dan kerusakan DAS akibat penggunaan lahan yang tidak menerapkan kaidah-kaidah konservasi. Kota Padang merupakan daerah rawan banjir di Provinsi Sumatera Barat, yang disebabkan oleh intensitas hujan yang tinggi dengan durasi waktu yang lama. Pengendalian banjir tidak bisa terlepas dari pentingya pengelolaan DAS. Melalui penerapan metode Zero Run Off System (ZROS) yang dapat meminimalkan aliran permukaan (run-off) dan meningkatkan penyerapan air. Sumur resapan salah satu yang direkomendasikan pada bagian hilir DAS Kuranji. Jumlah sumur resapan yang dibutuhkan adalah sebanyak 12.244 unit untuk periode ulang curah hujan 2 tahun dan 16.864 unit untuk periode ulang curah hujan 50 tahun.

Kata Kunci- banjir, DAS kuranji, run-off, zero run off system
\end{abstract}

\section{PENDAHULUAN}

Daerah Aliran Sungai (DAS) memiliki peran penting karena berfungsi sebagai perlindungan terhadap seluruh bagian DAS. Aliran permukaan merupakan salah satu faktor penyebab terjadi banjir akibat jumlah curah hujan yang jatuh dipermukaan tanah melampaui kapasitas infiltrasi. Kota Padang merupakan salah satu daerah rawan banjir yang disebabkan oleh intensitas hujan yang tinggi dengan durasi waktu yang lama. Menurut Badan Penanggulangan Bencana Daerah (BPBD) Provinsi Sumatera Barat tahun 2018 mencatat sebanyak 33 kali telah terjadi banjir di Kota Padang dalam jangka waktu 10 tahun terakhir. Daerah Aliran Sungai (DAS) Kuranji merupakan DAS terbesar diantara enam DAS di Kota Padang dengan debit dan volume aliran permukaan yang besar pada saat musim hujan mengakibatkan langsung menggenangi sebagian besar daerah bagian hilir DAS Kuranji.

Parameter yang menyebabkan terjadinya banjir adalah kelerengan yang curam, alih fungsi lahan, sistem drainase tidak memadai, pengundulan hutan di daerah hulu, dan terbatasnya upaya pemeliharaan (Berd, 2017). Banyak upaya yang telah dilakukan pemerintah dengan tujuan untuk pengendalian banjir. Salah satu contohnya adalah pembangunan cekdam di kawasan hulu DAS Kuranji namun hingga saat ini belum maksimal karena memerlukan biaya yang besar dan waktu pengerjaan yang lama.

Salah satu upaya konkrit yang dapat dilakukan untuk pengendalian banjir adalah melalui penerapan metode Zero Run Off System (ZROS). Metode Zero Run Off System (ZROS) merupakan teknik meminimalkan aliran permukaan (run-off) yang terjadi pada musim hujan, sehingga pada suatu wilayah tidak menghasilkan aliran permukaan (Ekaputra, 2014). Contoh bangunan yang menerapkan metode ZROS adalah sumur resapan. Sumur resapan berupa prasarana yang berfungsi untuk menampung aliran permukaan dan menyimpannya ke dalam tanah melalui infiltrasi dan perkolasi (Kusnaedi, 2006). Bentuk sumur resapan adalah berbentuk persegi atau silinder (BSN, 2002).

\section{METODOLOGI PENELITIAN}

Penelitian ini dilakukan pada kawasan DAS Kuranji Kota Padang yang dilaksanakan pada bulan Juli 2019 - bulan September 2019. Alat yang digunakan dalam penelitian ini adalah seperangkat komputer untuk menjalankan program ArcGIS 10.4.1, Global Positioning System (GPS), seperangkat alat tulis dan kamera digital. Tahap awal penelitian ini adalah pengumpulan data, adapun data yang dibutuhkan yaitu: data debit tahunan 10 tahun terakhir, data Digital Elevation Model (DEM), data iklim, peta jenis tanah, dan peta penggunaan lahan DAS Kuranji. Diagram alir penelitian dapat dilihat pada Gambar 1. 


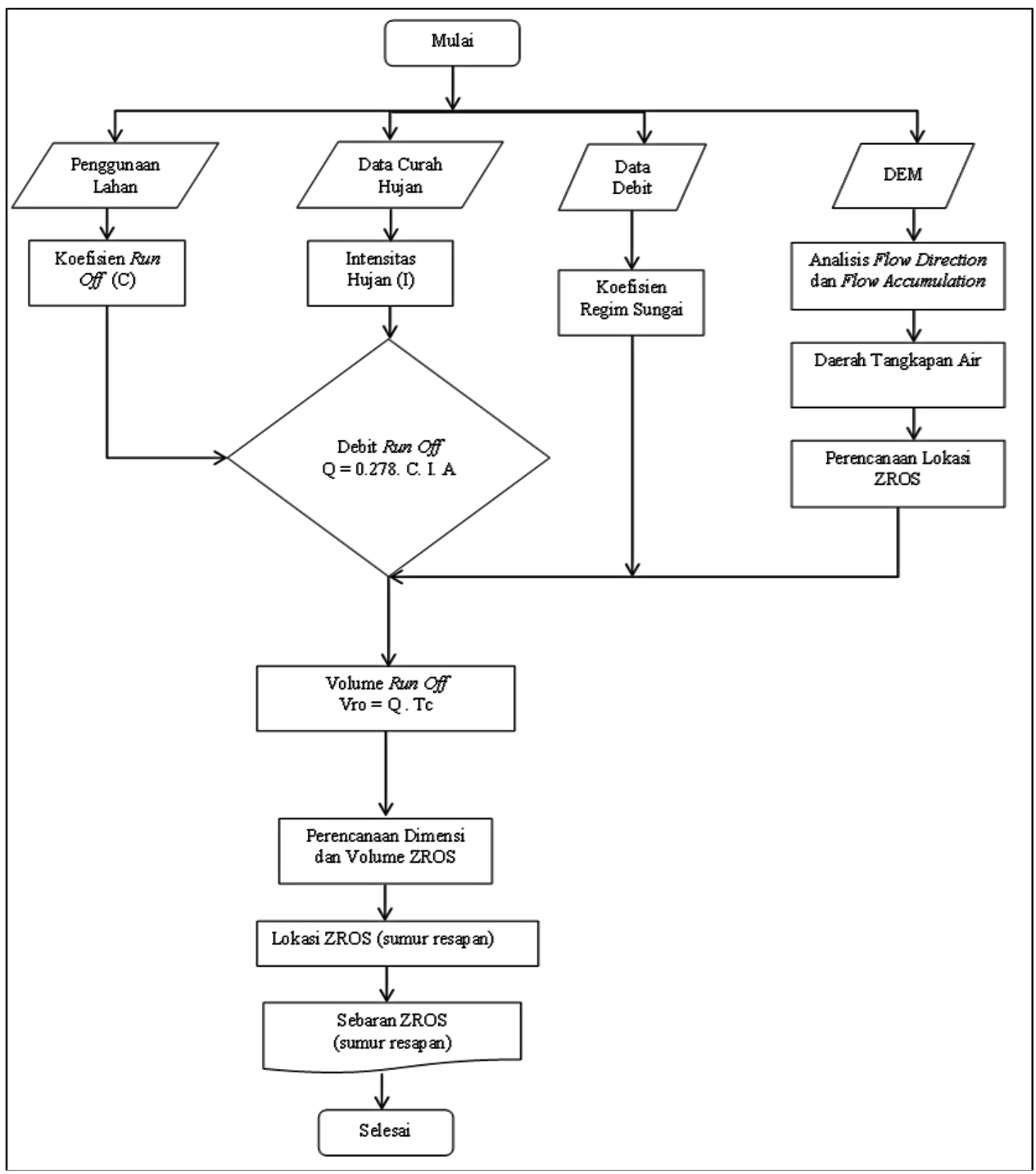

Gambar 1. Diagram Alir Penelitian

\section{A. Analisis Debit Aliran Permukaan}

Analisis debit aliran permukaan dilakukan dengan menggunakan persamaan rasional yang bertujuan untuk merancang bangunan pengendalian banjir (Asdak, 2014) dengan persamaan matematis sebagai berikut:

$\mathrm{Q}=0,278$. C. I. A

keterangan:

$\mathrm{Q}=$ Debit aliran permukaan $\left(\mathrm{m}^{3} /\right.$ detik $)$

$\mathrm{C}=$ Koefisien aliran permukaan

I $\quad=$ Intensitas curah hujan $(\mathrm{mm} / \mathrm{jam})$

A $\quad=$ Luas daerah tangkapan air $\left(\mathrm{km}^{2}\right)$

\section{B. Analisis Volume Aliran Permukaan}

Analisis volume aliran permukaan bertujuan untuk mengetahui banyaknya jumlah sumur resapan yang dibutuhkan. Persamaan yang digunakan untuk menghitung volume aliran permukaan sebagai berikut:

$V r=Q . T c$

keterangan:

$\mathrm{Vr}=$ Volume aliran permukaan $\left(\mathrm{m}^{3}\right)$

$\mathrm{Q}=$ Debit aliran permukaan $\left(\mathrm{m}^{3} /\right.$ detik)

$\mathrm{Tc}=$ Waktu konsentrasi (jam) 
Waktu konsentrasi (Tc) dapat dihitung dengan persamaan Kirpich (1940) sebagai berikut:

$T c=\frac{(0,87 \times L)^{2}}{(1000 X S)^{0,385}}$

keterangan:

$\mathrm{Tc}=$ Waktu konsentrasi (jam)

$\mathrm{L}=$ Panjang alur sungai $(\mathrm{km})$

$\mathrm{S}=$ Kemiringan rata-rata sungai

\section{Analisis Volume Sumur Resapan}

Bentuk sumur resapan yang digunakan dalam penelitian adalah berbentuk persegi, dan untuk menghitung volumenya digunakan persamaannya sebagai berikut:

$V s r=S \times S \times T$

keterangan:

$\mathrm{Vsr}=$ Volume sumur serapan $\left(\mathrm{m}^{3}\right)$

$\mathrm{S}=$ Sisi sumur resapan $(\mathrm{m})$

$\mathrm{T}=$ Kedalaman sumur resapan $(\mathrm{m})$

$\mathrm{J} s r=\frac{V r}{V s r}$

Persamaan yang digunakan untuk mencari jumlah sumur resapan sebagai berikut:

Keterangan:

$\mathrm{Jsr}=$ Jumlah sumur resapan (unit)

$\mathrm{Vr}=$ Volume aliran permukaan $\left(\mathrm{m}^{3}\right)$

$\mathrm{Vsr}=$ Volume sumur resapan $\left(\mathrm{m}^{3}\right)$

\section{HASIL DAN PEMBAHASAN}

\section{A. Gambaran Umum DAS Kuranji}

Secara geografis DAS Kuranji terletak pada $100^{0} 21^{\prime} 0^{\prime \prime}-100^{0} 33^{\prime} 0^{\prime \prime}$ Bujur Timur dan $0^{0} 56^{\prime} 40^{\prime \prime}$ $0^{0} 40^{\prime} 0 "$ Lintang Selatan dengan luas 215,615 $\mathrm{km}^{2}$ (Gambar 2). Panjang sungai keseluruhan (sungai utama dan anak-anak sungai) DAS Kuranji adalah 274,750 km dengan panjang sungai utama 32,410 $\mathrm{km}$. Topografi DAS Kuranji pada bagian hulu bergunung dan berbukit, pada bagian tengah dan hilir DAS tampak landai dan datar. Pola drainase DAS Kuranji termasuk dalam tipe dendritik. DAS Kuranji memiliki tingkat kelerengan yang beragam yaitu datar, landai, agak curam, curam sangat curam. Jenis tanah DAS Kuranji menurut Badan Perencanaan dan Pembangunan Daerah (BAPPEDA) Kota Padang memiliki lima jenis tanah yaitu: latosol, aluvial, andosol, organosol, dan regosol.

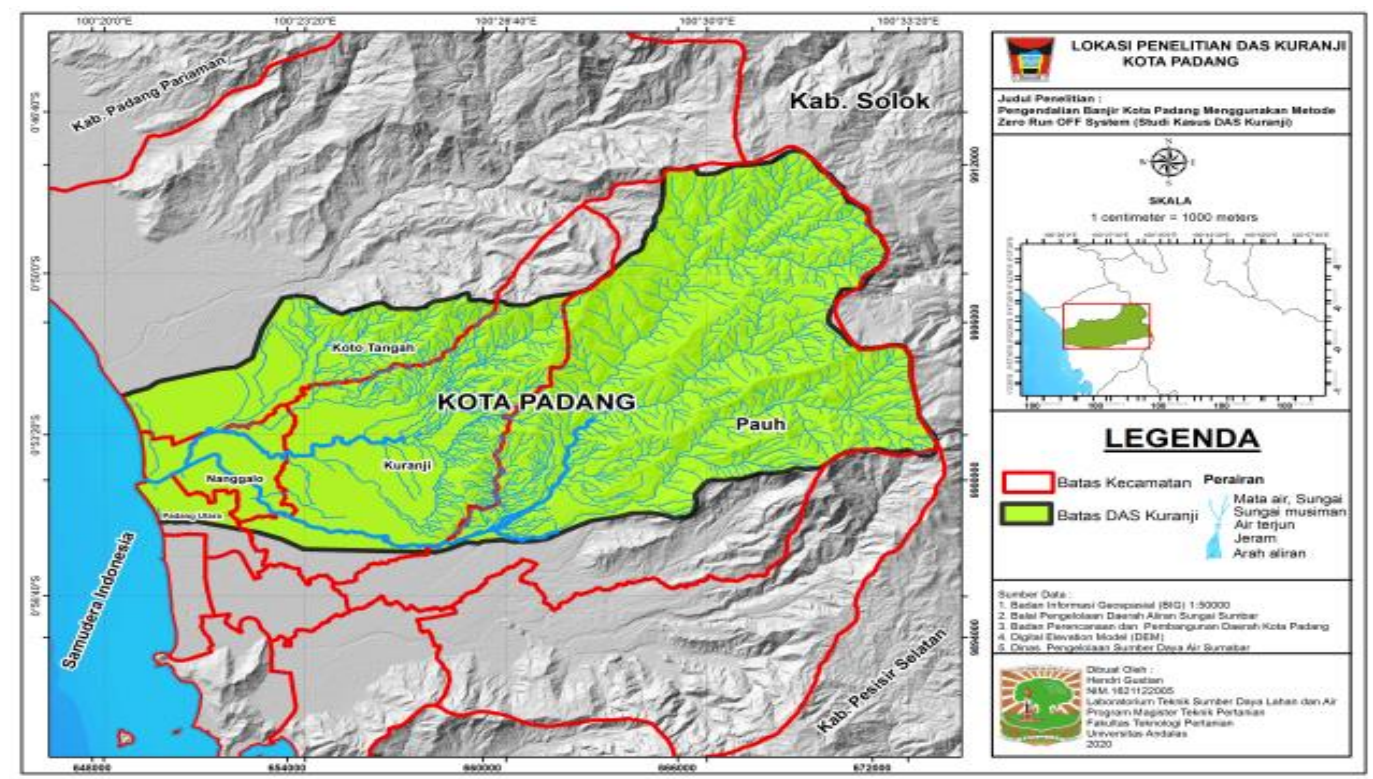

Gambar 2. Peta Lokasi Penelitian DAS Kuranji

Sumber: Badan Perencanaan Pembangunan Daerah Kota Padang (2018) 


\section{B. Analisis Debit Aliran Permukaan}

Penggunaan metode rasional direkomendasikan untuk DAS berukuran kecil, namun untuk DAS berukuran yang lebih luas maka perlu dibagi menjadi beberapa DTA (sub-DAS). Metode ini terbuki paling praktis dalam menduga debit dan volume aliran permukaan yang bertujuan untuk merancang bangunan pengendalian banjir (Asdak, 2014).

Tabel 1. Debit Aliran Permukaan DAS Kuranji ( $\mathrm{m}^{3} /$ detik)

\begin{tabular}{cccccccc}
\hline \multirow{2}{*}{ DTA } & 1 & 2 & 5 & 10 & 25 & 50 & 100 \\
\hline DTA 1 & 59,216 & 97,647 & 112,703 & 120,668 & 129,110 & 134,500 & 139,276 \\
DTA 2 & 36,989 & 60,996 & 70,400 & 75,376 & 80,649 & 84,016 & 86,999 \\
DTA 3 & 32,676 & 53,884 & 62,192 & 66,588 & 71,246 & 74,221 & 76,856 \\
DTA 4 & 11,897 & 19,618 & 22,643 & 24,243 & 25,939 & 27,022 & 27,981 \\
DTA 5 & 10,458 & 17,245 & 19,904 & 21,311 & 22,802 & 23,754 & 24,597 \\
DTA 6 & 14,487 & 23,889 & 27,573 & 29,522 & 31,587 & 32,906 & 34,074 \\
DTA 7 & 13,962 & 23,023 & 26,573 & 28,451 & 30,441 & 31,712 & 32,838 \\
DTA 8 & 21,553 & 35,541 & 41,021 & 43,920 & 46,993 & 48,955 & 50,693 \\
DTA 9 & 10,329 & 17,033 & 19,659 & 21,048 & 22,521 & 23,461 & 24,294 \\
DTA 10 & 8,583 & 14,079 & 16,250 & 17,398 & 18,615 & 19,392 & 20,081 \\
DTA 11 & 17,860 & 29,452 & 33,993 & 36,396 & 38,942 & 40,568 & 42,008 \\
DTA 12 & 10,690 & 17,628 & 20,346 & 21,784 & 23,307 & 24,281 & 25,143 \\
Total & 248,653 & 410,036 & 473,256 & 506,705 & 542,153 & 564,788 & 584,841 \\
\hline Sumber: Hasil Analisis & $(2019)$ & \multicolumn{7}{c}{} & &
\end{tabular}

Sumber: Hasil Analisis (2019)

Kawasan bagian hulu DAS Kuranji menghasilkan debit aliran permukaan yang cukup besar pada saat musim hujan, dengan tingkat kelerengan yang sangat curam. Kondisi mengakibatkan potensi banjir pada bagian hilir DAS Kuranji cukup besar karena pada saat musim hujan air terakumulasi pada bagian hilir (Gambar 3).

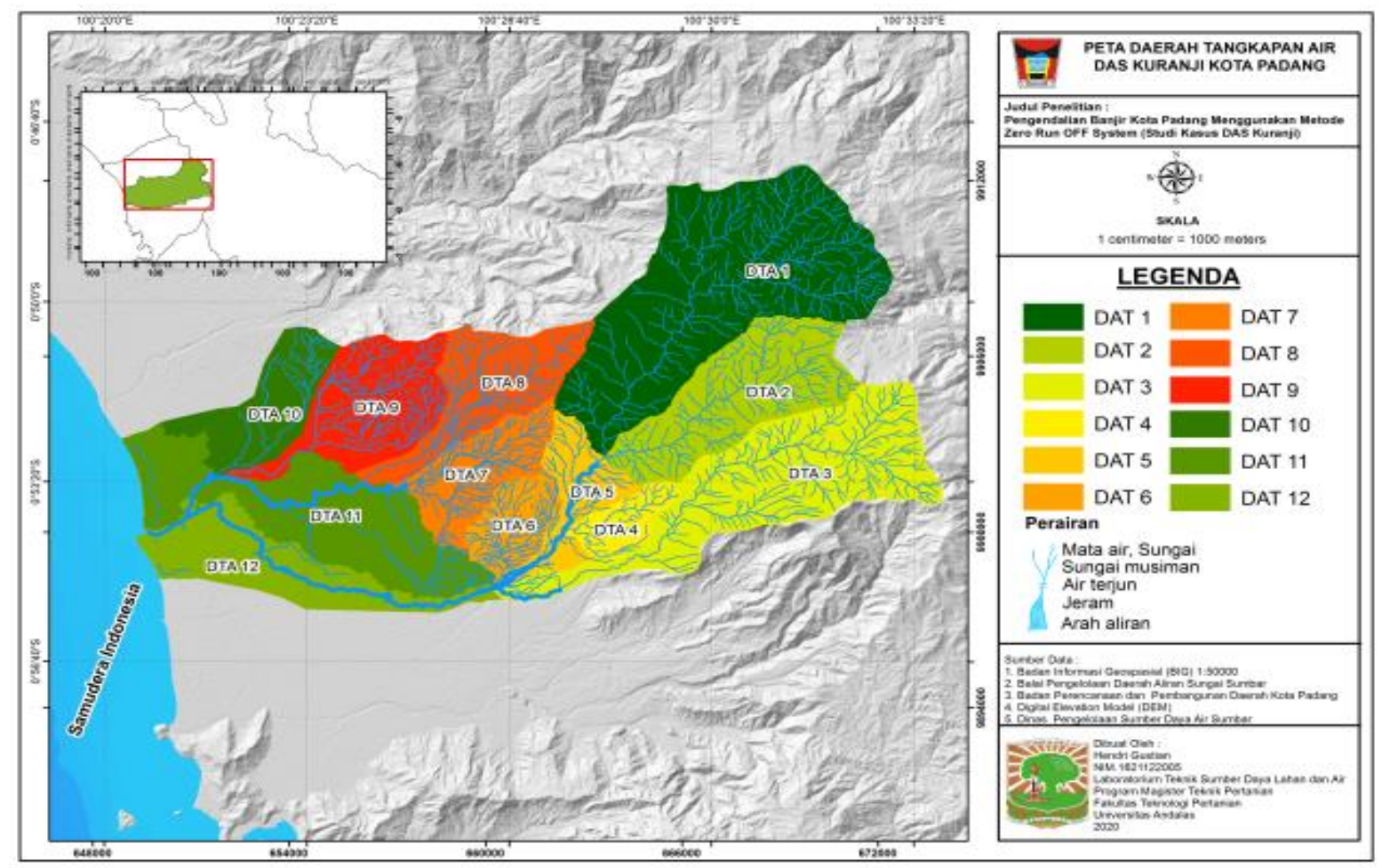

Gambar 3. Peta Daerah Tangkapan Air DAS Kuranji Sumber: Hasil Analisis (2019) 


\section{Analisis Volume Aliran Permukaan}

Pada musim hujan dengan intensitas yang tinggi kapasitas infiltrasi akan terlampaui dengan beda yang cukup besar dibandingkan dengan hujan yang kurang intensif, sehingga total volume aliran permukaan akan lebih besar pada saat hujan intensif, karena hujan dengan intensitas hujan yang tinggi dapat menurunkan kemampuan infiltrasi (Asdak, 2014). Luas DTA berbanding lurus dengan volume aliran permukaan, semakin luas DTA semakin besar volume aliran permukaan. Volume aliran permukaan yang besar pada bagian hulu DAS Kuranji dengan kelerengan yang sangat curam mengakibatkan potensi banjir pada bagian hilir DAS Kuranji. Hal ini dikarenakan kawasan bagian hilir DAS Kuranji tersebut merupakan kawasan padat pemukiman dan daerah resapan air yang kecil, sehingga perlu upaya pembuatan sumur resapan untuk meminalkan aliran permukaan.

Tabel 2. Volume Aliran Permukaan DAS Kuranji $\left(\mathrm{m}^{3}\right)$

\begin{tabular}{cccccccc}
\hline \multirow{2}{*}{ DTA } & 1 & 2 & 5 & 10 & 25 & 50 & 100 \\
\hline DTA 1 & 233.826 & 385.585 & 445.035 & 476.490 & 509.824 & 531.109 & 549.966 \\
DTA 2 & 90.055 & 148.503 & 171.399 & 183.514 & 196.325 & 204.549 & 211.812 \\
DTA 3 & 177.785 & 293.172 & 338.375 & 362.375 & 387.635 & 403.819 & 418.157 \\
DTA 4 & 16.656 & 27.467 & 31.702 & 33.942 & 36.317 & 37.833 & 39.176 \\
DTA 5 & 41.494 & 68.424 & 78.974 & 84.556 & 90.471 & 94.248 & 97.595 \\
DTA 6 & 26.346 & 43.445 & 50.143 & 53.687 & 57.443 & 59.841 & 61.966 \\
DTA 7 & 54.499 & 89.871 & 103.727 & 111.058 & 118.828 & 123.789 & 128.184 \\
DTA 8 & 67.489 & 111.291 & 128.450 & 137.529 & 147.150 & 153.294 & 158.736 \\
DTA 9 & 117.599 & 193.924 & 223.824 & 239.644 & 256.408 & 267.114 & 276.597 \\
DTA 10 & 73.965 & 121.971 & 140.777 & 150.726 & 161.271 & 168.004 & 173.969 \\
DTA 1 & 181.152 & 298.724 & 344.782 & 369.151 & 394.976 & 411.466 & 426.075 \\
DTA 12 & 113.973 & 187.944 & 216.922 & 232.253 & 248.501 & 258.876 & 268.068 \\
Total & 1.194 .839 & 1.970 .321 & 2.274 .110 & 2.434 .925 & 2.605 .149 & 2.713 .942 & 2.810 .301 \\
\hline
\end{tabular}

Sumber: Hasil Analisis (2019)

\section{Volume Sumur Resapan}

Dimensi sumur resapan yang digunakan adalah berbentuk persegi dengan ukuran $3 \mathrm{~m}$ x $3 \mathrm{~m} \mathrm{x}$ $5 \mathrm{~m}$ berdasarkan (SNI) 03-2453-2002 (BSN, 2002). Sehingga setiap sumur resapan mampu menampung aliran permukaan sebanyak $45 \mathrm{~m}^{3}$. Volume aliran permukaan dipengaruhi oleh laju infiltrasi. Berdasarkan penelitian Uthami (2017) laju infiltrasi DAS Kuranji $21,81 \mathrm{~mm} / \mathrm{jam}\left(4,711 \mathrm{~m}^{3} / \mathrm{hari}\right)$. sehingga jika dijumlahkan antara laju infiltrasi dan volume tampung sumur resapan maka daya tampung sumur resapan untuk mengurangi aliran permukaan menjadi semakin besar yaitu $49,771 \mathrm{~m}^{3} / \mathrm{hari}$.

Jumlah sumur resapan setiap DTA berbeda-beda, hal ini dipengaruhi oleh luas, debit dan volume aliran permukaan setiap DTA. Jumlah sumur resapan berbanding lurus dengan potensi aliran permukaan, semakin besar potensi aliran permukaan maka semakin banyak sumur resapan yang dibutuhkan. Pembangunan sumur resapan direkomendasikan pada daerah yang datar atau landai sehingga air yang mengalir dari daerah tinggi masuk ke sumur resapan secara optimal.

Sumur resapan dibangun pada DTA yang berpotensi terjadi banjir sejalan dengan pola drainase DAS Kuranji yang bertipe dendritik dimana potensi terjadinya banjir pada bagian hilir DAS. Oleh karena itu pembangunan sumur resapan direkomendasikan bagian hilir DAS Kuranji yang terdiri dari DTA 10 (sub-DAS Lubuk Gajah), DTA 11 (sub-DAS Sungai Sapih) dan DTA 12 (sub-DAS Kuranji Hilir). Sumur resapan yang dibutuhkan untuk mengurangi aliran permukaan pada bagian hilir DAS Kuranji adalah sebanyak 12.244 unit untuk periode ulang curah hujan 2 tahun dan 16.864 unit untuk periode ulang curah hujan 50 tahun.

\section{KESIMPULAN}

Sumur resapan direkomendasikan untuk pengendalian banjir pada bagian hilir DAS Kuranji dengan jumlah 12.244 unit untuk periode ulang curah hujan 2 tahun dan 16.864 unit untuk periode ulang curah hujan 50 tahun. 


\section{DAFTAR PUSTAKA}

Asdak, C. 2014. Hidrologi dan Pengelolaan Daerah Aliran Sungai. Yogyakarta: Gadjah Mada University Press.

Berd, I. 2017. Kajian Morphometri Pada Daerah Aliran Sungai (DAS) Batang Kuranji Terhadap Debit Banjir. Padang: Universitas Andalas.

[BPBD] Badan Penanggulangan Bencana Daerah. 2018. Tren Kejadian Bencana Kota Padang. Sumatera Barat: Padang.

[BSN] Badan Standardisasi Nasional. 2002. Tata Cara Perencanaan Teknik Sumur Resapan Air Hujan untuk Pekarangan. Jakarta.

Ekaputra, Eri Gas. 2014. Aplikasi Zero Run Off di Lahan Perkebunan Sawit Dalam Upaya Konservasi Sumber Daya Air. Padang: Universitas Andalas.

Kirpich, T.P. 1940. Time of Concentration of Small Agricultural Watersheed. Civil Engineering. 10(6), 362.

Kusnaedi. 2006. Sumur Resapan untuk Pemukiman Perkotaan dan Pedesaan. Jakarta: Penebar Swadaya.

Uthami. F.R. Analisis Spasial Kemampuan Infiltrasi Tanah DAS Kuranji. [Skripsi]. Fakultas Teknologi Pertanian. Padang: Universitas Andalas. 